\title{
Accelerated Canine Distalization with Mini- screw-assisted Micro-osteoperforations: A Case Report
}

\author{
Mini Vida Destekli Mikroosteoperforasyonlarla \\ Yapılan Hızlandırılmış Kanin Distalizasyonu
}

\begin{abstract}
Orthodontic treatment is aimed at increased life quality by improving the dentofacial functions and aesthetics of the individual. However, orthodontic treatment that takes 2-2.5 years on average both affects the psychological motivation of the patients and leads to a number of undesirable conditions such as caries, gingival recession, and root resorption, especially when the patient is inattentive to oral hygiene. Accordingly, many studies on accelerating orthodontic tooth movement (OTM) have been conducted recently. Microosteoperforation (MOP) is a recently developed microinvasive technique of tooth movement acceleration. This paper reports the effective and accelerated canine distalization obtained by mini-screw-assisted MOPs in the case of a 15-year-old female patient with Class II malocclusion, proclined maxillary incisors, and midline diastema. This technique compared to the conventional methods provided accelerated canine movement.

Keywords: tooth movement; acceleration
\end{abstract}

\section{Öz}

Ortodontik tedavinin amacı bireyin dentofasiyal fonksiyonlarını ve estetiğini geliştirerek yaşam kalitesini artırmaktır. Fakat ortalama 2-2,5 yıl süren ortodontik tedavi hem hastaların psikolojik motivasyonlarını etkilemekte hem de hastanın ağız hijyenine dikkat etmediği durumlarda çürük, dişeti çekilmesi ve kök rezorpsiyonu gibi birçok istenmeyen duruma yol açmaktadır. Bu sebeple son yıllarda ortodontik diş hareketinin hızlandıııması üzerine birçok çalışma yapılmıştır. Mikroosteoperforasyon (MOP) tekniği, son dönemde geliştirilmiş mikroinvaziv bir diş hareketi hızlandırma tekniğidir. Bu vaka raporunda, Sınıf II maloklüzyo$\mathrm{nu}$, protruziv keser dişleri ve orta hat diyasteması olan 15 yaşındaki kız hastada mini vida ile uygulanan MOP'larla yapılan etkili ve hızlandırılmış kanin distalizasyonu anlatılıştır. Konvansiyonel yöntemlere kıyasla bu teknikle kanin dişin hareketi hızlanmıştır.

Anahtar Sözcükler. diş hareketi; hızlandırma
Tuğba Haliloğlu Özkan', Selim ArıCl'$^{1}$, Nursel Arıcl', Enes Özkan²

Department of Orthodontics, Faculty of Dentistry, Ondokuz Mayıs University, Samsun, Turkey

2 Department of Oral and Maxillofacial Surgery, Bafra Oral and Dental Health Hospital Samsun, Turkey
Geliş Tarihi /Received : 10.04.2018 Kabul Tarihi /Accepted: 15.06.2018

DOI: 10.21673/anadoluklin.414302

Sorumlu Yazar/Corresponding Author Tugba Haliloglu Ozkan

Department of Orthodontics, Faculty of Dentistry, Ondokuz Mayıs University, 55139 Atakum, Samsun, Turkey E-mail: dttuuba@gmail.com 


\section{INTRODUCTION}

The growing awareness of good health has increased the demand for orthodontic treatment. The duration of orthodontic treatment is the most important factor negatively affecting the treatment process. Prolonged treatment not only affects the psychosocial state of the patient, but also increases the risk for periodontal disease, tooth decay, and root resorption (1). For this reason, in recent years, researchers have been working hard to develop various methods to accelerate tooth movement. Although many surgical techniques and physical and chemical applications have been reported in the literature to accelerate tooth movement, uncertainties and unanswered questions about these are still present and need to be investigated (2-4).

The technique of controlled microtrauma (microosteoperforations-MOPs) to the alveolar bone has been shown to increase the release of the naturally released inflammatory markers during orthodontic treatment, which in turn accelerates osteoclastic activity and increases the OTM rate (5). Teixeria et al. reported performing superficial and limited perforations (MOPs) on the buccal cortical bone portion of maxilla of rats, significantly increasing the rate of OTM (6). Perforations are made by inserting the mini-screw into the desired depth between the tooth roots through both the labile and the attached mucosa. The mini-screw used penetrates through the cortical to medullary bone. Performance of MOPs is the same as placement of mini-screws. The procedure is flapless. Subsequently, Alikhani et al. reported tooth movement with MOPs at a rate 2.3-fold higher than that in the non-affected region (5). However, in that study, it was stated that further research was needed regarding the parameters (number, depth and frequency) of the technique.

The MOP technique is a minimally invasive surgical method that has many advantages among other methods. Performing MOPs does not require special training; the operation time is limited to few minutes; and patients can continue their daily life immediately after the procedure. New clinical trials on humans are needed because, to the best of our knowledge, there is only one published human study in the literature (5). If the ideal parameters of the technique can be determined in humans, use of the body's own natural interdependent bone remodeling routes without any external intervention will significantly shorten the time for OTM, maximize patient comfort, and provide exceptional cost of care. This case report originally describes the effectiveness of mini-screw-assisted 5-mm deep MOPs on the OTM.

\section{CASE REPORT}

\section{Diagnosis and etiology}

A girl aged 15 years and 2 months presented to our clinic with the chief complaint of proclined maxillary incisors. The clinical examination showed a convex profile, mild interincisal spacing, flared maxillary incisors. (Figure 1 and 2) Overbite was $4 \mathrm{~mm}$ and overjet was $6 \mathrm{~mm}$. There was Class II relationship on both sides; no buccal or lingual crossbites were examined. Permanent dentition was completed; there was no missing or malformed teeth. The patient had a good oral hygiene and no radiographic evidence of bone loss was observed. The patient had no specific signs or symptoms of temporomandibular disorders.

Cephalometric evaluation showed a skeletal Class II sagittal relationship $\left(\mathrm{ANB}=7.5^{\circ}\right.$ ), a normal maxilla (A to $\mathrm{N}$ perpendicular, $1 \mathrm{~mm}$ ), and a retrusive mandible (A to $\mathrm{N}$ perpendicular, $-12.3 \mathrm{~mm}$ ). Protrusive upper (U1 to SN, 105, $2^{\circ}$ ) and lower (IMPA, $101^{\circ}$ ) incisors were also observed. (Figure 3 )

\section{Treatment objectives}

The treatment objectives were to improve the profile, correct the Class II molar and canine relationship, establish an ideal overjet and overbite, improve incisor inclination, eliminate interincisal spacing, and achieve a good functional occlusion.

\section{Treatment alternatives}

First, non-extraction treatment with fixed functional appliances was considered. This option can allow for great profile improvement by causing a large amount of lower incisor protrusion when the lower incisors are not severely protruded. However, cephalometric analysis already showed protruded lower incisors in this case.

The second option was upper molar distalization. Thus, all upper dentition could be distalized and Class I canine and molar relationship could be achieved. Ideal overjet, overbite and occlusal relationships could 


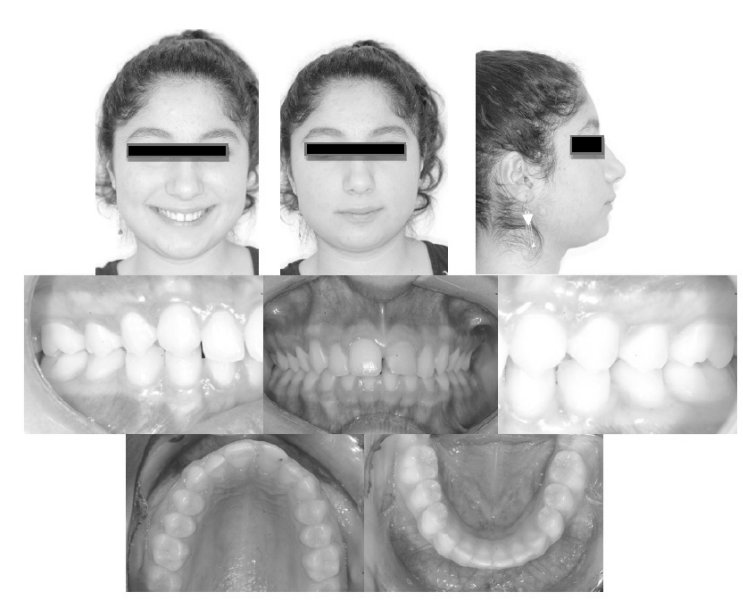

Figure 1. Pretreatment intraoral and facial photographs

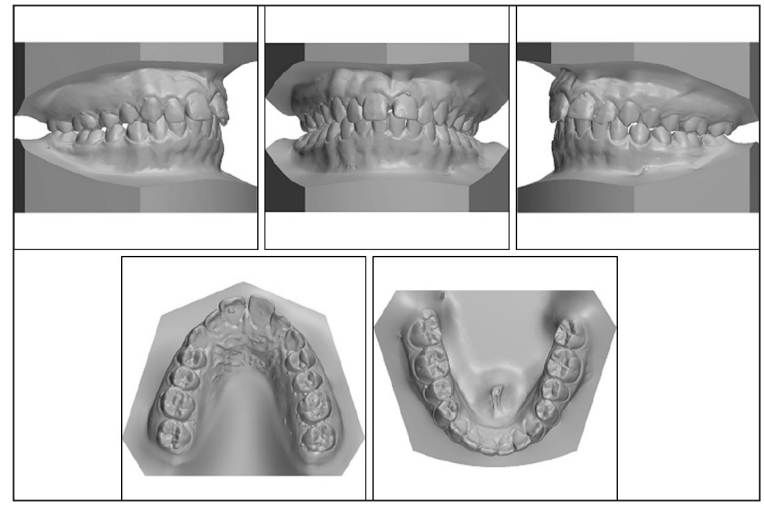

Figure 2. Pretreatment study models

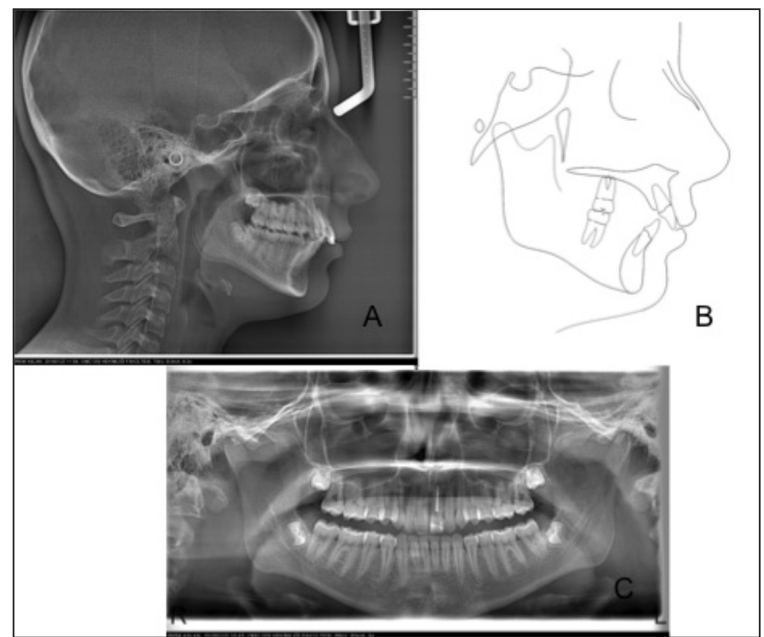

Figure 3. Pretreatment. A. cephalometric radiograph, B. tracing, C. panoramic radiograph

be obtained without tooth extraction. Even so, facial profile would not positively change, and facial convexity and the total treatment time would increase.
The third option was maxillary premolar extractions with moderate anchorage. This option would eliminate increased overjet, achieve Class I canine relationship, and obtain good occlusal relationships. However, it would not correct the Class II molar relationship, and facial profile would not significantly improve.

After reviewing the treatment options with the patient and her parents, the patient was unwilling to wear a functional appliance or a headgear and thus chose the third option. However, the parent's main concern was about the duration of the treatment because she was not in favor of having to wear braces for a couple of years. Accordingly, we considered accelerating the tooth movement. After detailed explanation, the patient and parents gave informed consent to the treatment with MOPs.

\section{Treatment progress}

Extractions were performed after the initial records (photos, alginate impressions, OPG and cephalometric radiograph) were obtained. The treatment was initiated by bonding the fixed appliances $(0.022$ " McLaughin, Bennett, and Trevisi-MBT- prescription) in both arches after one week of tooth extraction. Passive lacebacks were performed, and a transpalatal arch was placed in the maxilla. The arches were then leveled and aligned (0.014" heat-activated NiTi [HANT; 3M Unitek, Monrovia, CA, USA]; 0.016" HANT; and 0.019 "-0.025" HANT). Distalization was performed on passive 0.019 " $-0,025$ " stainless steel arch wire. A mini-screw (MTN-2, DesignMed, İstanbul, Turkey) with a diameter of $1.6 \mathrm{~mm}$ and a length of $8 \mathrm{~mm}$ was modified by placing four elastomeric ligatures on the body of the mini-screw (Figure 4). The required perforation depth was set to $5 \mathrm{~mm}$. Subsequently, the miniscrews were sterilized with elastomeric ligatures and then prepared for the surgical procedure.

Infiltration anesthesia ( $0.5 \mathrm{ml}$ Ultracain DS Forte) was applied at the region of perforations. Three MOPs were performed in the distal aspects of the canine teeth as close to the apical as possible to achieve more bodily movement and were aligned vertically toward the attached gingiva (Figure 5) Care was taken to ensure a distance of one mini-screw diameter between each perforation. Mini-screws were also placed between the roots of the second premolar and those of the first molar teeth to support anchorage. A force of 
$150 \mathrm{~g}$ was applied by ligating the calibrated NiTi closing coil spring (Sentalloy, 3M Unitek, USA) between the orthodontic mini-screw and the canine bracket hook with a 0.010 " ligature wire for canine distalization. The applied force was measured by a force gauge at the beginning, fourth, and eighth weeks of distalization, and it was adjusted to remain constant.

The MOP procedure was repeated at the fourth week of distalization. Alginate impressions and photographs were taken at the beginning of the treatment and at the beginning, first, fourth, and eighth weeks of distalization. The distalization was concluded at the fourth week for the right canine and eighth week for the left canine of the distalization period. (Figure 6)

The models were scanned and digitized by a software program (Orthoanalyzer, 3Shape, Copenhagen, Denmark). The first, fourth and eighth week models were superimposed with the distalization beginning model. Superimposition was made on the third palatal rugae in the maxilla. In the mandible, the lower central incisors and the second molars were used as superimposition reference points. The software program was used to measure canine distalization (CD) and molar mesialization (MM) in $\mathrm{mm}$, canine rotation $(\mathrm{CR})$ and canine tipping $(\mathrm{CT})$ in degrees.

\section{RESULTS}

Treatment of a patient with Class II malocclusion resulted in an ideal overjet and overbite, Class I canine relationship, and midline diastema closure in a short time. Good aesthetic and occlusal results were achieved. (Figure 7 and 8)

Cephalometric analysis and Bjork's structural total/local superimpositions showed that the maxillary incisors were uprighted ( $\mathrm{U} 1$ to $\mathrm{SN}, 92^{\circ}$ ), and mandibular incisor inclination was maintained (IMPA, $101.4^{\circ}$ ). ANB angle decreased $7.5^{\circ}$ to $5.5^{\circ}$ (Table 1 ; Figure 9 and 10).

For all time intervals, both right and left canines moved faster than the conventional methods. Molar mesialization was minuscule, but a significant tipping angle was measured for both sides. The data of the patient are summarized in Table 2. Class I canine relationship was achieved in eight weeks. Total treatment time was 10 months.

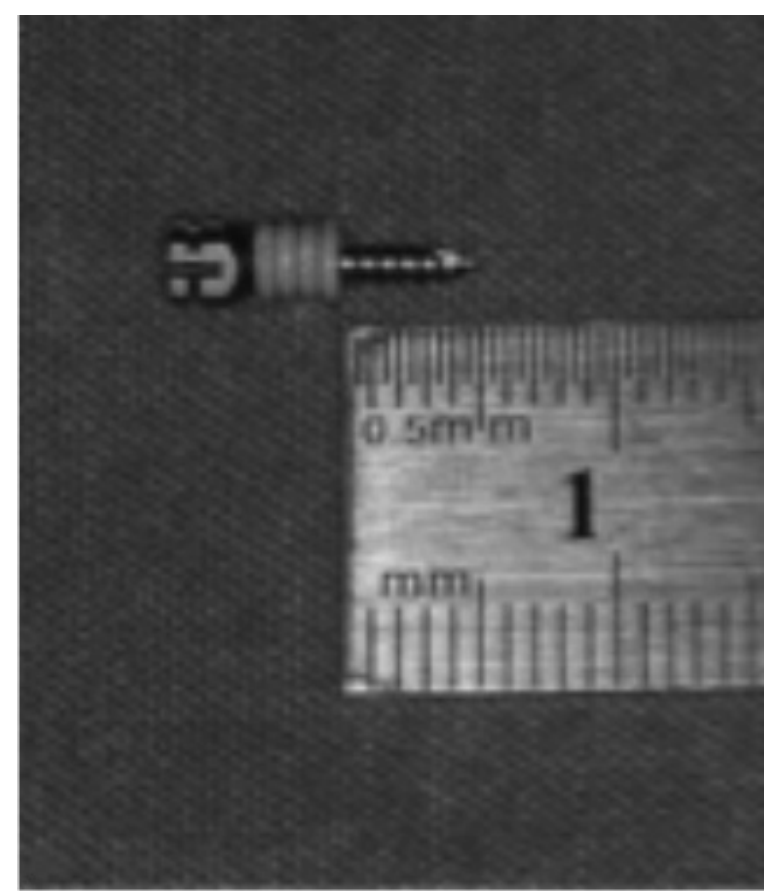

Figure 4. Modified mini-screw

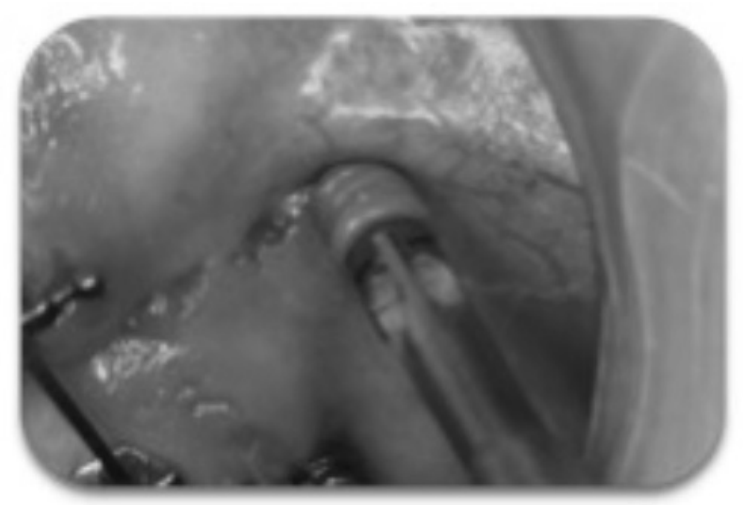

Figure 5. Micro-osteoperforations

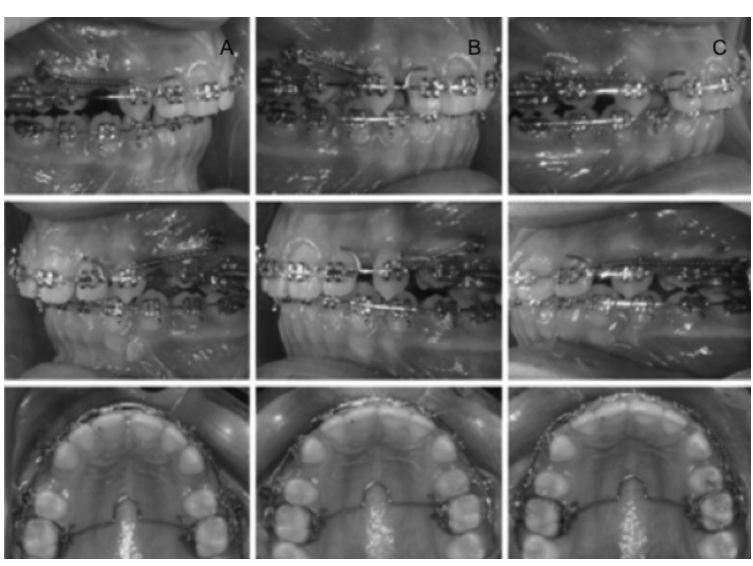

Figure 6. A. Beginning of the distalization period (T1), B. Fourth week of distalization (T3), C. Eighth week of distalization (T4) 


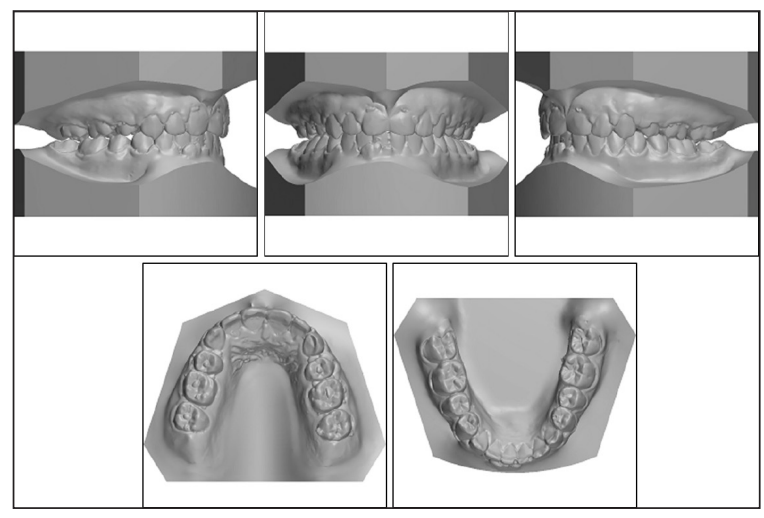

Figure 7. Posttreatment. A. cephalometric radiograph, B. tracing, C. panoramic radiograph

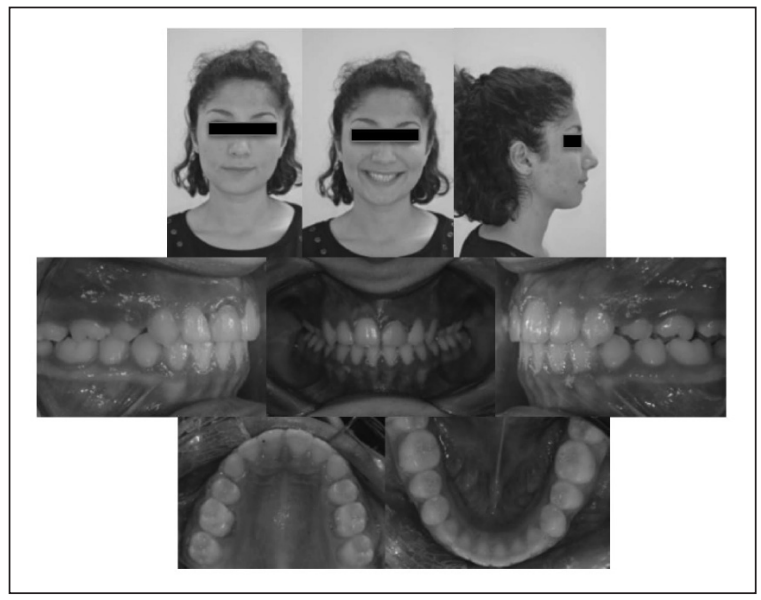

Figure 8. Posttreatment intraoral and facial photographs
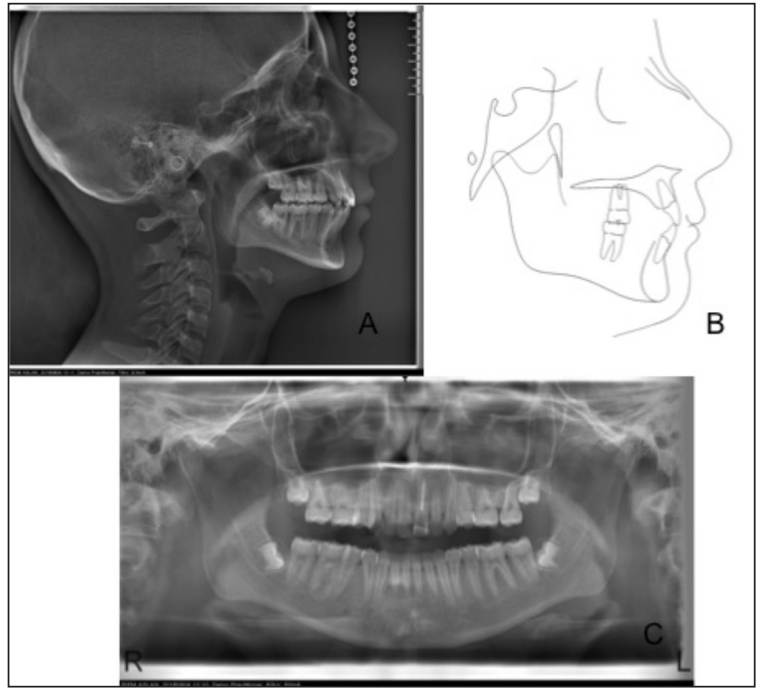

Figure 9. Posttreatment study models

\section{DISCUSSION}

Researchers have argued that controlled microtrauma into the alveolar bone increases the discharge of the naturally released inflammatory markers during orthodontic treatment (6). In this way, osteoclastic activity can accelerate, thereby increasing bone resorption and tooth movement. Alikhani et al. showed that 3 MOPs at a 2-3-mm depth could increase the rate of CD by more than twofold (5). We performed 3 MOPs at a $5-\mathrm{mm}$ depth at the distal aspect of the canine teeth. The mean depth was determined given that the perforations to be performed at depths less than $5 \mathrm{~mm}$ could not cross over the gingival thickness at the distal aspect of the canine through the medullary bone.

We performed MOPs with mini-screws while Alikhani et al. used a specially designed handpiece (5). Because of the orthodontic mini-screw similarity of this handpiece, choosing mini-screws for performing MOPs in future studies will bring considerable advantages like ease of application, accessibility and cost. The dependency on this specially designed tool in performing MOPs will be removed.

Canine distalization with conventional methods is one of the most time-consuming parts of the treatment. The monthly rate of OTM is 0.8 to $1.2 \mathrm{~mm}$ when continuous forces are applied in cases of treatment with conventional methods (7). Tsai et al. compared the effects of MOPs and cortision on the rate of OTM. Researchers reported an acceleration of 1.54 times in the MOP group and 1.49 times in the corticision group compared to the control group (8). Baloul et al. reported that tooth movement was 1.3 times faster on day 42 after 10 micro-osteoperforations with flap elevation in rats (9). Cho et al. reported that the tooth movement distance increased 4.41 times in the maxilla and 2.44 times in the mandible after applying 24 decortication dots with flap surgery in dogs (10). Aksakallı et al. reported that the amount of canine distalization in patients who had undergone piezoincision, a minimally invasive surgical method, was $1.53 \mathrm{~mm}$ in the first and $1.37 \mathrm{~mm}$ in the second month (11). In our case, canine distalization was found to be $2.29 \mathrm{~mm}(0.081$ $\mathrm{mm}$ /day) for the right and $2.53 \mathrm{~mm}(0.090 \mathrm{~mm} /$ day $)$ for the left region. A large amount of the acceleration occurred at the first week of the MOP $(0.76 \mathrm{~mm})$. This 
acceleration could be due to the effect of the MOPs on damaging the spongiosis structure of the maxilla. Considering the available data in the literature, the amount of distalization was greater in all time intervals compared to those achieved by the conventional methods, while this acceleration is consistent with the values of mean acceleration reported in other studies. In addition, considering the differences in tissue structure, life cycle, and physiological response to tooth movement between humans and animals, the optimal surgery parameters, biomechanical force systems, and frequency of application for humans are still unknown and further studies are needed.

MOPs appear to lead to tipping on canine teeth, and have no effect on the molar anchorage loss. It was suggested that, by weakening the cortical bone around the canine and preserving the integrity of the bone in the molar region, the coil used for retraction could work on a differential anchorage principle between the anterior and posterior regions, which could reduce the expected anchorage loss in the molar teeth. Thus, accelerating the rate of the canine tooth will not lead to more anchorage loss in the molar teeth $(12,13)$. These effects should be investigated in more detail in randomized clinical trials.

The information on how long the regional acceleration phenomenon (RAP) effect lasts after trauma varies in the literature $(14,15)$. Alikhani et al. reported that all the inflammatory markers except IL-1 decreased to the pre-retraction levels by the 28th day of distalization (5). Considering the decreased effectiveness of the surgical insult on the fourth week of retraction (and, therefore, the level of cytokines and RAP response), we replaced the OPs at T3. Findings demonstrate that replacing MOPs could not trigger the movement rate when RAP is at a certain level.

In retrospect, the posterior settling might have been better, especially on the right side, and the miniscule spaces distal to the canines could have been entirely closed. The major factor for those is the patient's desire to finish the treatment as soon as possible.

No MOP-related complication was observed in this case. The patient did not report pain or discomfort during the treatment.

This report demonstrates that MOPs as performed in this case can successfully accelerate canine distaliza-
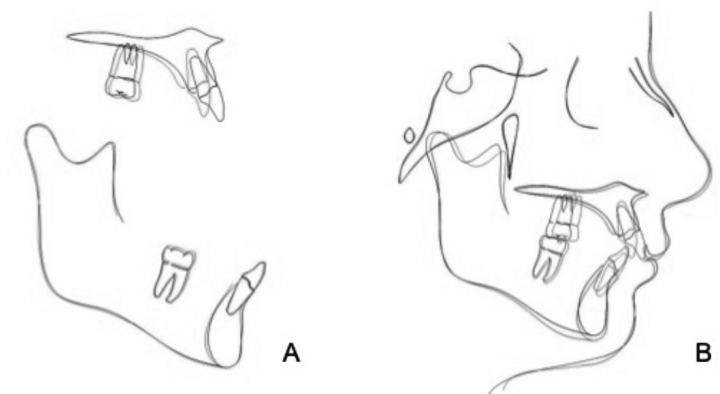

Figure 10. Pre-posttreatment cephalometric superimpositions. A. local, B. total

Table 1. Changes in cephalometric measurements

\begin{tabular}{lcc} 
& Pretreatment & Posttreatment \\
\cline { 2 - 3 } SNA & 82.5 & 80.5 \\
Maxillary Skeletal (A-Na Perp) $(\mathrm{mm})$ & 1.0 & -1.3 \\
SNB & 74.9 & 75.0 \\
Pog-N Perpendicular (mm) & -12.3 & -12.5 \\
ANB & 7.5 & 5.5 \\
U1-SN & 106.2 & 97.1 \\
IMPA & 101.0 & 101.4
\end{tabular}

Table 2. Data of the patient

\begin{tabular}{|c|c|c|c|c|c|c|}
\hline & \multicolumn{2}{|c|}{$T 2$} & \multicolumn{2}{|c|}{$T 3$} & \multicolumn{2}{|c|}{$T 4$} \\
\hline & RIGHT & LEFT & RIGHT & LEFT & RIGHT & LEFT \\
\hline$C D(\mathrm{~mm})$ & 0,9 & 0,86 & 2,29 & 2,53 & 0 & 3,88 \\
\hline $\operatorname{CT}\left({ }^{\circ}\right)$ & 3,7 & 2,6 & 7,9 & 7,7 & 0 & 11,5 \\
\hline$C R\left({ }^{\circ}\right)$ & 1,2 & 2,2 & 3,9 & 4,6 & 0 & 5,9 \\
\hline$M M(\mathrm{~mm})$ & 0 & 0,1 & 0,1 & 0,2 & 0 & 0,2 \\
\hline
\end{tabular}

CD: canine distalization; CT: canine tipping; CR: canine rotation; MM: molar mesialization

tion. Side effects due to prolonged treatment time can be minimized by this microinvasive method. Largesample randomized clinical studies with attention to side effects and cost-benefit analysis are needed to detail the protocols for the current method capable of accelerating the OTM.

\section{REFERENCES}

1. Nimeri G, Kau CH, Abou-Kheir NS, Corona R. Acceleration of tooth movement during orthodontic treatmenta frontier in orthodontics. Prog Orthod. 2013;14:42.

2. Sukurica Y, Karaman A, Gurel HG, Dolanmaz D. Rapid canine distalization through segmental alveolar distraction osteogenesis. Angle Orthod. 2007;77(2):226-36.

3. Stark TM, Sinclair PM. Effect of pulsed electromagnetic fields on orthodontic tooth movement. Am J Orthod 
Dentofacial Orthop. 1987;91(2):91-104.

4. Collins MK, Sinclair PM. The local use of vitamin D to increase the rate of orthodontic tooth movement. Am J Orthod Dentofacial Orthop. 1988;94(4):278-84.

5. Alikhani M, Raptis M, Zoldan B, Sangsuwon C, Lee YB, Alyami B, et al. Effect of micro-osteoperforations on the rate of tooth movement. Am J Orthod Dentofacial Orthop. 2013;144(5):639-48.

6. Teixeira CC, Khoo E, Tran J, Chartres I, Liu Y, Thant LM, et al. Cytokine expression and accelerated tooth movement. J Dent Res. 2010;89(10):1135-41.

7. Andrade I, Jr, Sousa AB, da Silva GG. New therapeutic modalities to modulate orthodontic tooth movement. Dental Press J Orthod. 2014;19(6):123-33.

8. Tsai CY, Yang TK, Hsieh HY, Yang LY. Comparison of the effects of micro-osteoperforation and corticision on the rate of orthodontic tooth movement in rats. Angle Orthod. 2016;86(4):558-64.

9. Baloul SS, Gerstenfeld LC, Morgan EF, Carvalho RS, Van Dyke TE, Kantarci A. Mechanism of action and morphologic changes in the alveolar bone in response to selective alveolar decortication-facilitated tooth movement.
Am J Orthod Dentofacial Orthop. 2011;139(4):83-101.

10. Cho KW, Cho SW, Oh CO, Ryu YK, Ohshima H, Jung HS. The effect of cortical activation on orthodontic tooth movement. Oral Dis. 2007;13(3):314-9.

11. Aksakalli S, Calik B, Kara B, Ezirganli S. Accelerated tooth movement with piezocision and its periodontaltransversal effects in patients with Class II malocclusion. Angle Orthod. 2016;86(1):59-65.

12. Aslan BI, Baloştuncer B, Dinçer M. Are there differences on tooth movement between different sectional canine retractors? J Orofac Orthop. 2013;74(3):226-35.

13. Ziegler P, Ingervall B. A clinical study of maxillary canine retraction with a retraction spring and with sliding mechanics. Am J Orthod Dentofacial Orthop. 1989;95(2):99-106.

14. Camacho AD, Velasquez Cujar SA. Dental movement acceleration: literature review by an alternative scientific evidence method. World J Methodol. 2014;4(3):151-62.

15. Gkantidis N, Mistakidis I, Kouskoura T, Pandis N. Effectiveness of non-conventional methods for accelerated orthodontic tooth movement: a systematic review and meta-analysis. J Dent. 2014;42(10):1300-19. 